\title{
Communication \\ Optimization of Different Acid-Catalyzed Pretreatments on Co-Production of Xylooligosaccharides and Glucose from Sorghum Stalk
}

\author{
Xiaocui Yang ${ }^{1}$, Xiaoliu Liu ${ }^{2}$, Yequan Sheng ${ }^{3, *}$, Hanzhou Yang ${ }^{3}$, Xinshuai Xu ${ }^{3}$, Yuheng Tao ${ }^{4}$ \\ and Minglong Zhang ${ }^{5,6, *}$
}

check for

updates

Citation: Yang, X.; Liu, X.; Sheng, Y.; Yang, H.; Xu, X.; Tao, Y.; Zhang, M. Optimization of Different Acid-Catalyzed Pretreatments on Co-Production of

Xylooligosaccharides and Glucose from Sorghum Stalk. Polymers 2022, 14, 830. https://doi.org/10.3390/ polym 14040830

Academic Editor: Sudip Chakraborty

Received: 8 January 2022

Accepted: 18 February 2022

Published: 21 February 2022

Publisher's Note: MDPI stays neutral with regard to jurisdictional claims in published maps and institutional affiliations.

Copyright: (C) 2022 by the authors. Licensee MDPI, Basel, Switzerland. This article is an open access article distributed under the terms and conditions of the Creative Commons Attribution (CC BY) license (https:// creativecommons.org/licenses/by/ $4.0 /)$.
1 Engineering Training Center, Nanjing Vocational University of Industry Technology, Nanjing 210023, China; 2019010152@niit.edu.cn

2 College of Bioscience and Engineering, Hebei University of Economics and Business, Shijiazhuang 050061, China; liuxiaoliu@heuet.edu.cn

3 Jiangsu Co-Innovation Center of Efficient Processing and Utilization of Forest Resources, International Innovation Center for Forest Chemicals and Materials, College of Materials Science and Engineering, Nanjing Forestry University, Nanjing 210037, China; 1352124091@njfu.edu.cn (H.Y.); limimingjun@163.com (X.X.)

4 Department of Bioengineering, School of Pharmacy \& School of Medicine, Changzhou University, Changzhou 213164, China; cztyh0305@163.com

5 College of Materials Science and Engineering, Central South University of Forestry and Technology, Changsha 410004, China

6 Anhui Hongsen Hi-Tech Forestry Co., Ltd., Bozhou 233600, China

* Correspondence: shengyequan@njfu.edu.cn (Y.S.); zmlong2008@126.com (M.Z.)

\begin{abstract}
There is an increasing emphasis on the transformation of lignocellulosic biomass into versatile products. The feasibility of preparing xylooligosaccharides (XOS) by hydrolysis of sorghum stalk (SS) using organic and inorganic acids was studied. The influences of different acids (gluconic acid, acetic acid, sulfuric acid, and oxalic acid), process time and temperature on the hydrolysis of SS were explored. The findings indicated XOS yield can be maintained at a high level under different conditions with organic acid pretreatments. Optimum yield of XOS (39.4\%) was obtained using sulfuric acid ( $\mathrm{pH} 2.2)$ at $170{ }^{\circ} \mathrm{C}$ and $75 \mathrm{~min}$ of process time. It is suggested when reaction temperature and time were increased, both $\mathrm{X} 5$ and $\mathrm{X} 6$ are cracked into $\mathrm{XOS}$ with lower molecular mass such as X2, X3, and X4. Moreover, the results based on mass balance showed that up to $110 \mathrm{~g}$ (XOS) plus $117 \mathrm{~g}$ (glucose) can be recovered from $1000 \mathrm{~g}$ of SS. Results will give insights into establishing an efficient acid pretreatment of sorghum stalk to coproduction of XOS and glucose.
\end{abstract}

Keywords: sorghum stalk; xylooligosaccharide; acid hydrolysis; enzymatic hydrolysis; glucose

\section{Introduction}

Consistent efforts have been adopted using renewable lignocellulosic material as feedstock to produce value-added products in the biorefinery industry, such as biofuel, biomaterial [1-3]. Lignocellulosic material represents the primary constituents of biomass that comprising mainly the complex polymeric compounds of lignin, multiple cross-linked structures of cellulose and hemicellulose [4]. It is generally known that both hemicellulose and cellulose can be hydrolyzed by enzyme or chemical treatment into glucose and xylose for subsequent conversion into valuable feedstocks for instance xylonic acid and ethanol $[5,6]$.

However, due to the presence of crystalline and high polymerization degree of cellulose that embedded/connected to the lignin and hemicellulose, the overall lignocellulosic material shows high resistance to enzyme and chemical treatment [7].

Sorghum stalk (SS) (a residue of the sorghum production) accounts for about $35 \%$ of the total sorghum mass. About 1.4 million tons of SS is generated in China every year, 
more than half of those SS are burned directly without proper reusing strategy. Since SS is found with $30-45 \%$ cellulose and $25-30 \%$ xylan-type hemicellulose [8], hence it is hypothesized that the SS could be an encouraging material to refine versatile materials such as fermentable sugars and XOS [9] rather than recovering no value from burning.

Hemicellulose is the second abundant lignocellulosic material in nature with various degree of polymerization [10]. Xylooligosaccharides (XOS) is the product resulted from hydrolysis of xylan-type hemicellulose that has lower degree of polymerization. This includes xylobiose (X2), xylotriose (X3), xylotetraose (X4), xylopentaose (X5), and xylohexaose $(\mathrm{X} 6)[11,12]$. At present, $\mathrm{XOS}$ is often used as a functional ingredient to stimulate the growth of prebiotic activity in the intestine for improvement of immunity. In addition, XOS could also be applied in food, animal feed and pharmaceutical fields as well as to reduce cholesterol levels and the risk of colon cancer [13].

Suitable pretreatment approach represents a crucial step to resolve the cellulose entanglement for effective utilization of lignin, hemicellulose and cellulose. Lately, the widely explored pretreatment methods of lignocellulose materials include steam explosion, acidsbased thermal pretreatment, solvent extraction and biological pretreatment [14,15]. Acid pretreatment is an effective way to ease the conversion of cellulosic biomass into biochemical [16]. It is a commonly used chemical pretreatment technology to remove cellulose by degrading it into oligosaccharides. Acid pretreatment is considerably low cost and suitable for the production of biochemical $[17,18]$. During acid pretreatment reaction, the glycosidic bonds between the hemicellulose will be broken which subsequently facilitates the degradation of cellulose into oligosaccharides and monosaccharides in the later enzymatic hydrolysis [19]. However, there has not been detailed research on the production of biochemicals from SS using various acid with different strength.

Organic acids have lower $\mathrm{pKa}$ values and thus provides milder acid condition than mineral acids, such as sulfuric acid. As an organic acid, they may impart a more readily tuned, optimized, and efficient hydrolysis of various lignocellulosic substrates over a range of temperatures and times compared to stronger mineral acids. Therefore, in this research, different types of acid (i.e., oxalic acid, sulfuric acid, gluconic acid, acetic acid) pretreatments was applied to produce XOS and glucose from SS. The influences of different acids, the process time and temperature to perform hydrolysis on the composition and yield of XOS were investigated. Subsequently, the ability of enzymatic hydrolysis of residual cellulose were systematically analyzed. Further, the mass balance diagrams for the overall process is presented to demonstrate the effectiveness. It was observed the great potential of using acid pretreatment on SS to produce value-added biorefinery products.

\section{Materials and Methods}

\subsection{Materials}

Sorghum stalk (Sorghum bicolor var. kaoliang) (SS) was collected from a farmland in Shandong Province, China, directly after crop harvest. After air-drying, the stalks were chipped using an industry-scale Drum-Chipper. The chips were then reduced into powders using a laboratory-scale grinding miller. These SS powders were sieved using a 40-mesh sieve followed by mild drying at $60^{\circ} \mathrm{C}$ in an electric oven for 1 day, the dried SS contained $4.2 \%$ moisture. Sulfuric acid (SA), oxalic acid (OA), gluconic acid (GA), acetic acid (AA) were purchased from Macklin, China. The $p K a$ values of sulfuric acid, oxalic acid, gluconic acid and acetic acid were $-2.0,1.27,3.86$ and 4.74 , respectively. Distilled water was used as reaction medium whenever necessary.

\subsection{Evaluation of Acid Pretreatment}

The acid pretreatment process was assessed via CSF (also known as combined severity factor), which consolidates the data of various combinations of process time ( $\mathrm{min}$ ) and temperature $\left({ }^{\circ} \mathrm{C}\right)$ used to perform hydrolysis. 
The CSF was calculated as following [20]:

$$
\begin{gathered}
\mathrm{CSF}=\log \left(R_{0} \times\left[H^{+}\right]\right)=\log R_{0}-p H \\
R_{0}=\mathrm{t} \times \exp \left[\left(\mathrm{T}_{h}-\mathrm{T}_{r}\right) / \mathrm{w}\right]
\end{gathered}
$$

where $\mathrm{T}_{h}$ and $\mathrm{T}_{r}$ refer to the hydrolysis temperature and base temperature $\left(100{ }^{\circ} \mathrm{C}\right)$, respectively. $\mathrm{w}$ refers to fitting parameter constant (14.75). The CSF has been specifically explained as the influence of acid pretreatment in the materials. It originated in the use of acidic pretreatment on biomass to estimate the solubilization of xylan and the reduction of lignin. The combined index was then used to further assess the influences of hydrolysis performed via various acids (SA, OA, GA and AA). The reaction $\mathrm{pH}$ in different acid pretreatments were uniformly adjusted to 2.2. The biomass to acid liquid ratio was 1:10. The combinations of reaction conditions were tabulated in Table 1 based on the previous studies $[19,21]$.

\begin{tabular}{|c|c|c|c|c|}
\hline \multirow{2}{*}{$\begin{array}{c}\text { Reaction } \\
\text { Acids/pH (2.2) }\end{array}$} & \multirow{2}{*}{ Run } & \multicolumn{2}{|c|}{ Variable } & \multirow{2}{*}{$\begin{array}{c}\text { Response } \\
\text { XOS Yield (\%) }\end{array}$} \\
\hline & & Temperature $\left({ }^{\circ} \mathrm{C}\right)$ & Time (min) & \\
\hline \multirow{9}{*}{ Acetic acid (AA) } & 1 & 127.8 & 60 & 2.0 \\
\hline & 2 & 135 & 45 & 2.8 \\
\hline & 3 & 135 & 75 & 13.0 \\
\hline & 4 & 152.5 & 38.8 & 29.1 \\
\hline & 5 & 152.5 & 45 & 33.2 \\
\hline & 6 & 152.5 & 60 & 38.6 \\
\hline & 7 & 152.5 & 81.2 & 29.7 \\
\hline & 8 & 170 & 45 & 18.3 \\
\hline & 9 & 170 & 75 & 2.2 \\
\hline \multirow{12}{*}{ Gluconic acid (GA) } & 10 & 180 & 45 & 0.1 \\
\hline & 1 & 127.8 & 60 & 1.2 \\
\hline & 2 & 135 & 45 & 5.2 \\
\hline & 3 & 135 & 75 & 10.3 \\
\hline & 4 & 152.5 & 38.8 & 23.4 \\
\hline & 5 & 152.5 & 45 & 26.2 \\
\hline & 6 & 152.5 & 60 & 32.1 \\
\hline & 7 & 152.5 & 81.2 & 30.7 \\
\hline & 8 & 170 & 45 & 27.1 \\
\hline & 9 & 170 & 75 & 7.7 \\
\hline & 10 & 180 & 45 & 2.9 \\
\hline & 1 & 127.8 & 60 & 1.1 \\
\hline \multirow{8}{*}{ Oxalic acid (OA) } & 2 & 135 & 45 & 2.7 \\
\hline & 3 & 135 & 75 & 2.9 \\
\hline & 4 & 152.5 & 38.8 & 3.0 \\
\hline & 5 & 152.5 & 45 & 7.6 \\
\hline & 6 & 152.5 & 60 & 15.6 \\
\hline & 7 & 152.5 & 81.2 & 20.6 \\
\hline & 8 & 170 & 45 & 24.3 \\
\hline & 9 & 170 & 75 & 27.5 \\
\hline \multirow{11}{*}{ Sulfuric acid (SA) } & 10 & 180 & 45 & 26.2 \\
\hline & 1 & 127.8 & 60 & 0.2 \\
\hline & 2 & 135 & 45 & 0.4 \\
\hline & 3 & 135 & 75 & 0.8 \\
\hline & 4 & 152.5 & 38.8 & 1.5 \\
\hline & 5 & 152.5 & 45 & 1.6 \\
\hline & 6 & 152.5 & 60 & 5.3 \\
\hline & 7 & 152.5 & 81.2 & 9.4 \\
\hline & 8 & 170 & 45 & 11.5 \\
\hline & 9 & 170 & 75 & 39.4 \\
\hline & 10 & 180 & 45 & 25.8 \\
\hline
\end{tabular}

Table 1. The xylooligosaccharides (XOS) yield of response surface analysis.

\subsection{Enzymatic Hydrolysis}

After acid pretreatments, the pretreated SS were hydrolyzed by cellulase (C2730) manufactured by Novozymes, Sigma Co. in Shanghai, China. Prior for enzymatic hydrolysis, the acid pretreated SS was constantly cleaned using distilled water for $6 \mathrm{~h}$ to eliminate 
the remaining acids and toxic aldehydes. Then, enzymatic hydrolysis of the cleaned acid pretreated SS was performed in a $25 \mathrm{~mL}$ screw-capped bottle and mixed with a dose of $20 \mathrm{FPIU} / \mathrm{g}$. The process was conducted for $108 \mathrm{~h}$ under a temperature of $50{ }^{\circ} \mathrm{C}$ and mild acidic $\mathrm{pH}$ (4.8) with constant shaking $(150 \mathrm{rpm})$ in a water bath. During enzymatic hydrolysis, the contents of glucose and cellobiose were quantified at 12 -h intervals in the enzymolysis solution.

\subsection{Analytical Methods}

The contents of lignin, hemicellulose and cellulose in the raw material and acid pretreated SS were resolved by the National Renewable Energy Laboratory method (NREL) [22] The xylobiose (X2), xylotriose (X3), xylotetraose (X4), xylopentaose (X5), and xylohexaose (X6) were quantified by high performance anion exchange chromatography-pulsed amperometric detector at $30^{\circ} \mathrm{C}$ (HPAEC-PAD, Dionex ICS-3000) with a CarboPacTM PA200 column using $\mathrm{NaOH}(100 \mathrm{mM})$ and $\mathrm{NaOAc}(500 \mathrm{mM})$ under constant flow rate of $0.3 \mathrm{~mL} / \mathrm{min}$ [23]. The contents of glucose, xylose and arabinose were quantified by high performance liquid chromatography at $55^{\circ} \mathrm{C}$ (HPLC, Agilent 1260) with analytical column (Aminex Bio-Rad $\mathrm{HPX}-87 \mathrm{H})$ adopting $\mathrm{H} 2 \mathrm{SO} 4(5 \mathrm{mM})$ at a fixed flow rate of $0.6 \mathrm{~mL} / \mathrm{min}$. All samples were physically refined through a $0.22 \mu \mathrm{m}$ membrane to eliminate solid impurities before analysis. Each experiment was repeated twice.

The yield of XOS and enzymatic hydrolysis were determined as follows:

$$
\begin{gathered}
\text { XOS yield }(\%)=\frac{(\mathrm{X} 2+\mathrm{X} 3+\mathrm{X} 4+\mathrm{X} 4+\mathrm{X} 6)(\mathrm{g}) \times 100}{\text { Initial xylan }- \text { based hemicellulose }(\mathrm{g})} \\
\text { Enzymatic hydrolysis yield }(\%)=\frac{(\text { cellobiose }+ \text { glucose }) \times 0.9(\mathrm{~g}) \times 100}{\text { Initial glucan content of materials }(\mathrm{g})}
\end{gathered}
$$

\section{Results and Discussion}

\subsection{XOS Yield by Four Kinds of Acid Pretreatments of Sorghum Stalk}

It is generally known that the lower dissociation constant of an acid, the greater of its ability to release $\mathrm{H}+$, hence causing more degradation of hemicellulose to XOS and monosaccharides. However, when comparing with strong organic acids at the same $\mathrm{pH}$ value, the concentrated AA could provide more stable and sufficient $\mathrm{H}+$ since AA is a weak electrolyte and hence lower dissociation balance (Table 1). Consequently, the presence of concentrated $\mathrm{H}+$ could enhance the rupture effects in pre-treatment of SS, and degrade the macromolecule xylan-based hemicellulose into smaller molecule of oligosaccharides [24]. The results showed that the weaker acid was conducive to the further degradation of XOS under the same $\mathrm{pH}$ condition.

\subsection{Influences of the Process Temperature and Time}

The influences of process temperature and time on the yield and components of XOS in the pretreatment of SS were shown in Figure 1. The highest XOS yield (38.6\%) was obtained from the pretreatment of AA for $60 \mathrm{~min}$ at $152.5^{\circ} \mathrm{C}$ with a constant $\mathrm{pH}$ (Figure 1). With an increase of temperature, XOS yield first increased and then decreased at $152.5^{\circ} \mathrm{C}$. While a sharp decrease in XOS yields occurred at reaction time $(60 \mathrm{~min})$ from $18.3 \%\left(170{ }^{\circ} \mathrm{C}\right)$ to $0.1 \%\left(180{ }^{\circ} \mathrm{C}\right)$. This indicates that hydrolysis performed under longer time plus high temperature conditions were unfavorable for XOS production. On the other hand, the XOS yield improved from $2.0 \%\left(127.8^{\circ} \mathrm{C}\right)$ to $38.6 \%\left(152.5^{\circ} \mathrm{C}\right)$ at the same reaction time (60 $\mathrm{min}$ ). This could be attributed to the use of relatively higher temperature accelerated the hydrolysis of xylan-type hemicellulose to low-molecular oligosaccharides. Noureddini and Byun [25] also reported the same phenomenon. In addition, the same findings were produced with OA and GA in which the XOS yields of were $27.5 \%\left(170{ }^{\circ} \mathrm{C}, 75 \mathrm{~min}\right)$ and $32.1 \%\left(152.5^{\circ} \mathrm{C}, 60 \mathrm{~min}\right)$, respectively. 


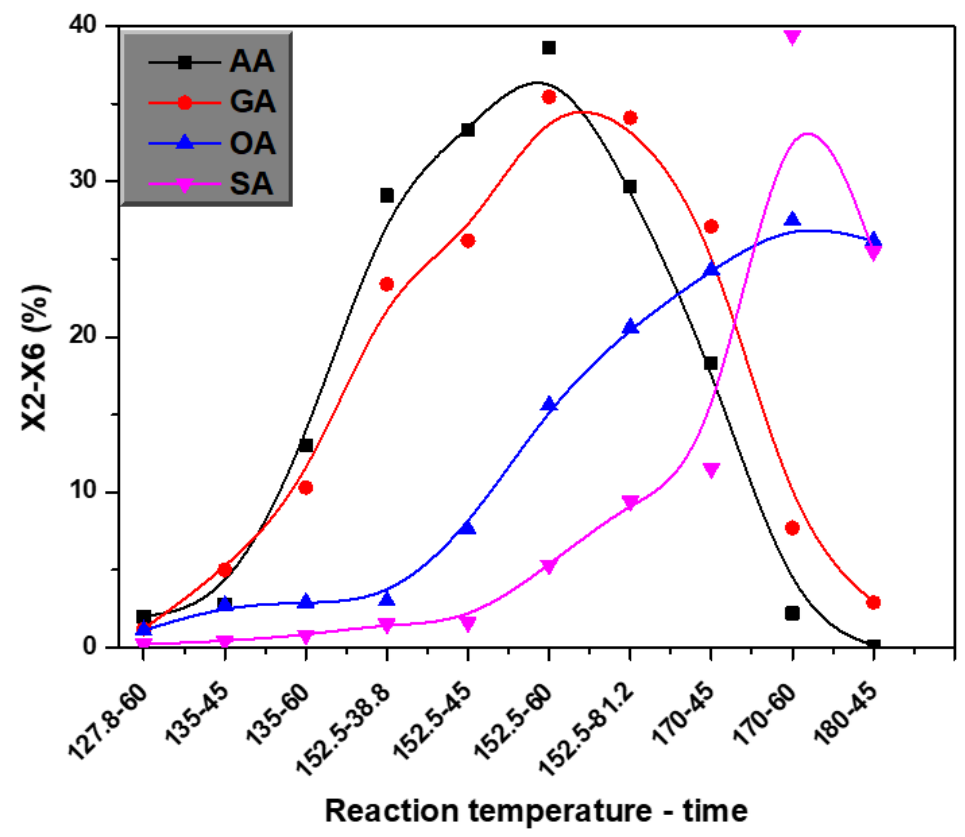

Figure 1. Influence of reaction temperature and time on xylooligosaccharides (XOS) yield.

Moreover, Figure 1 shows the XOS yield obtained from the hydrolysis of SS with AA and GA. As the time progress, the yield of XOS decreased. In comparison, the yield of XOS increased with longer reaction time using SA and OA. This indicates that the yield of XOS obtained from the degradation of hemicellulose was significantly affected by different acids used. In addition, it was noticed from the hydrolysis with various acids that higher temperature is required to optimize the yield of XOS when strong acid is used [19].

Figure 2 presents the relative content of $\mathrm{X} 2, \mathrm{X} 3, \mathrm{X} 4, \mathrm{X} 5, \mathrm{X} 6$ produced by SS under different reaction temperature and time. When the reaction temperature is increased, both $\mathrm{X} 5$ and $\mathrm{X} 6$ are cracked into XOS with lower molecular mass such as X2, X3 and X4. Same observations were obtained at different reaction time. The results showed that both process parameters (i.e., temperature and time) have noticeably influences on the molecular mass distribution of the resulted products. Figure $2 \mathrm{a}, \mathrm{b}$ demonstrate the influence of different reaction time on the yield of $X 2-X 6$. When the hydrolysis undergone longer, both $X 2$ and $\mathrm{X} 3$ increased whereas for $\mathrm{X} 5, \mathrm{X} 6$ and $>\mathrm{X} 6$, the hydrolysis process was continued until producing oligosaccharides with lower molecular mass such as $\mathrm{X} 2, \mathrm{X} 3$ and $\mathrm{X} 4$. It can be clearly observed that a relatively low yield of X5 and X6 was obtained at high temperature $\left(170{ }^{\circ} \mathrm{C}, 75 \mathrm{~min}\right)$ with organic acid pretreatment. Although the higher yield of XOS could be attained by the use of concentrated acid or prolong process time, the unwanted side products such as furfural, hydroxymethyl furfural and other harmful substances might be resulted [26].

\subsection{Enzymatic Hydrolysis of Sorghum Stalks for Fermentable Sugar Production}

When the maximum XOS was obtained by hydrolysis of SS with different acid pretreatment, the chemical properties of the pretreated solid fraction was identified (Table 2). In favor of optimizing the yield of the pretreated materials, the residues pretreated with different acids were mixed with $20 \mathrm{FPIU} / \mathrm{g}$ of glucan to perform the enzymatic hydrolysis under process time of $108 \mathrm{~h}$, the results are displayed in Figure 3. Among them, the enzymatic hydrolysis yield obtained from SS pretreated with OA and SA was the highest (exceeding $42 \%)$. Zhang et al. [27] obtained $43.6 \%$ yield from the combination of supercritical CO2 and ultrasonic pretreatment on SS. In this research, approximately 33\% yield were obtained from the enzymatic hydrolysis of AA and GA pretreated SS, while the XOS yields produced was $38.6 \%$ and $32.1 \%$, respectively, indicating that both AA and GA pretreatments fully removed the hemicellulose in the SS. 

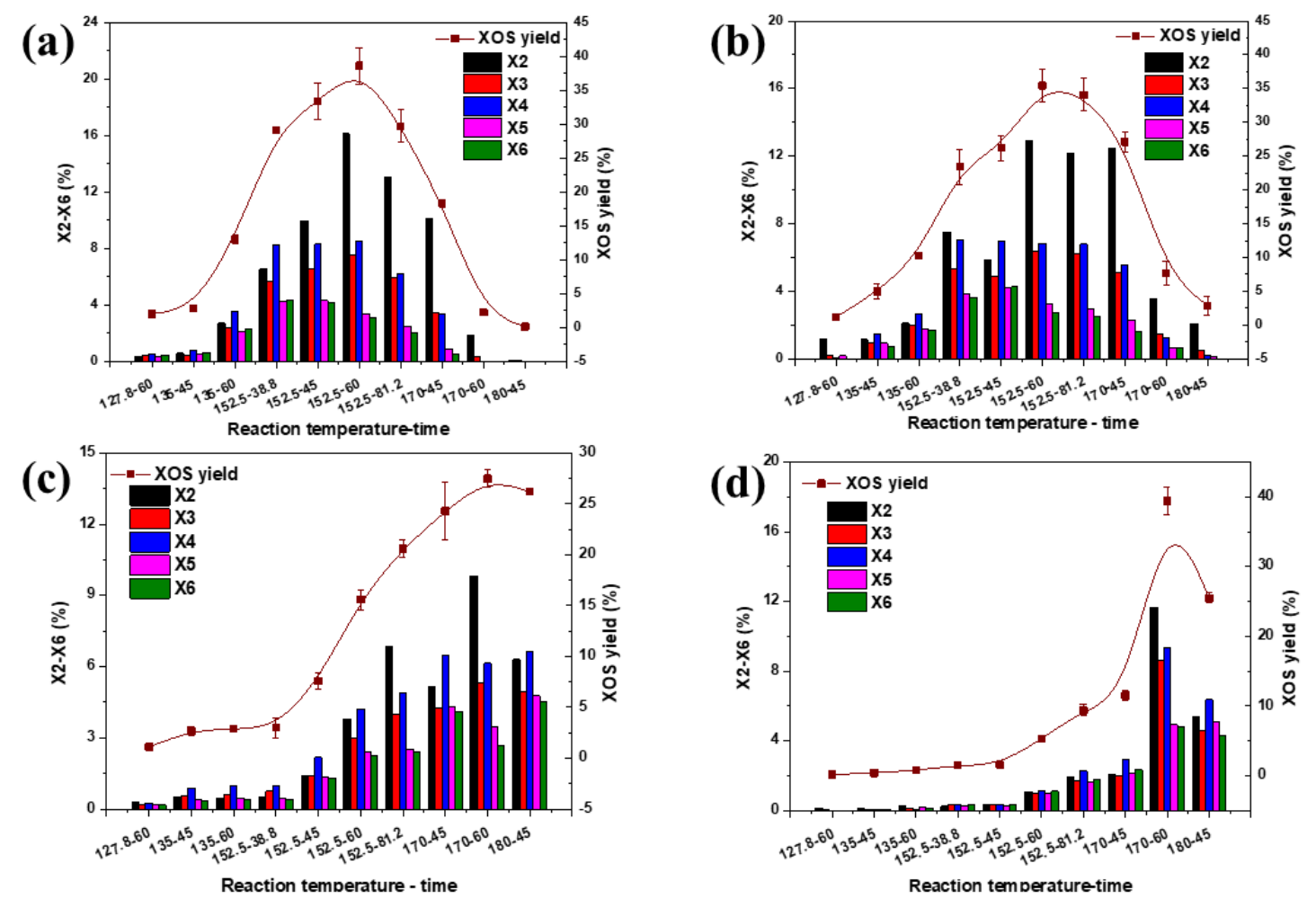

Figure 2. The yields of $\mathrm{X} 2-\mathrm{X} 6$ produced from sorghum stalks with different reaction temperature and time under different acids ((a) Acetic acid, (b) Gluconic acid, (c) Oxalic acid, (d) Sulfuric acid).

Table 2. Chemical composition of the solid fraction after acids treatment.

\begin{tabular}{ccccc}
\hline Samples & Cellulose (wt\%) & Xylan (wt \%) & Araban (wt\%) & Lignin (wt $\mathbf{o})$ \\
\hline SS & 33.6 & 27.4 & 2.7 & 23.5 \\
AA & 44.4 & 15.6 & $/$ & 25.2 \\
GA & 37.4 & 12.3 & $/$ & 25.4 \\
OA & 43.3 & 14.5 & $/$ & 24.9 \\
SA & 43.3 & 15.2 & & 24.5 \\
\hline
\end{tabular}

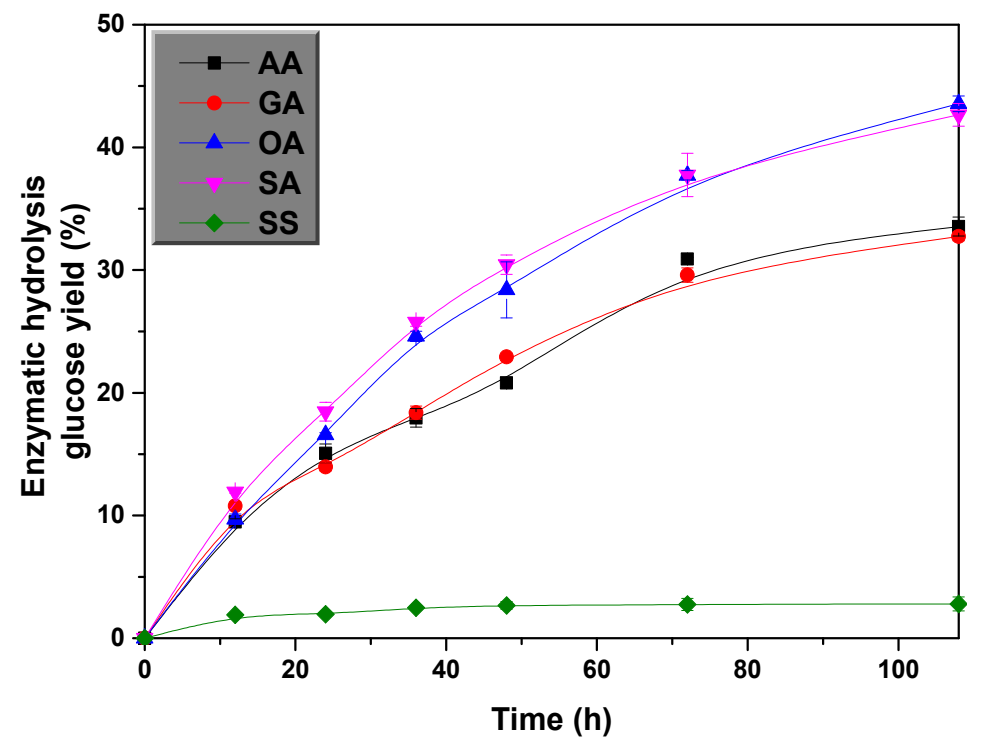

Figure 3. The $108 \mathrm{~h}$ enzymatic hydrolysis efficiency of SS subjected to different acids hydrolysis. 


\subsection{Mass Balance for Production of XOS and Glucose}

Figures 4 and S1-S3 illustrate the analysis of mass balance to produce XOS and glucose. About $1000 \mathrm{~g}$ of dried SS containing $336 \mathrm{~g}$ of glucan, $274 \mathrm{~g}$ of xylan, and $235 \mathrm{~g}$ of lignin. Up to $110.2 \mathrm{~g}$ of XOS and $619.0 \mathrm{~g}$ of solid fraction (containing $268 \mathrm{~g}$ glucan, $94 \mathrm{~g}$ xylan, $151 \mathrm{~g}$ lignin) were produced from SS treated with $\mathrm{SA}(\mathrm{pH}=2.2)$ for $75 \mathrm{~min}$ at $170{ }^{\circ} \mathrm{C}$ (Figure 4). When comparing with the SA hydrolysis used in Figure 4, the two-stage process of organic acid pretreatment and the enzymatic hydrolysis produced lower content of XOS and fermentative sugars (Figures S1-S3). In addition, XOS uses high-precision high performance anion exchange chromatography-pulsed amperometric detector (HPAECPAD) for analysis in this study. These results indicated that pretreatment of SS with SA in optimum condition was beneficial for XOS and fermentable sugars co-production.

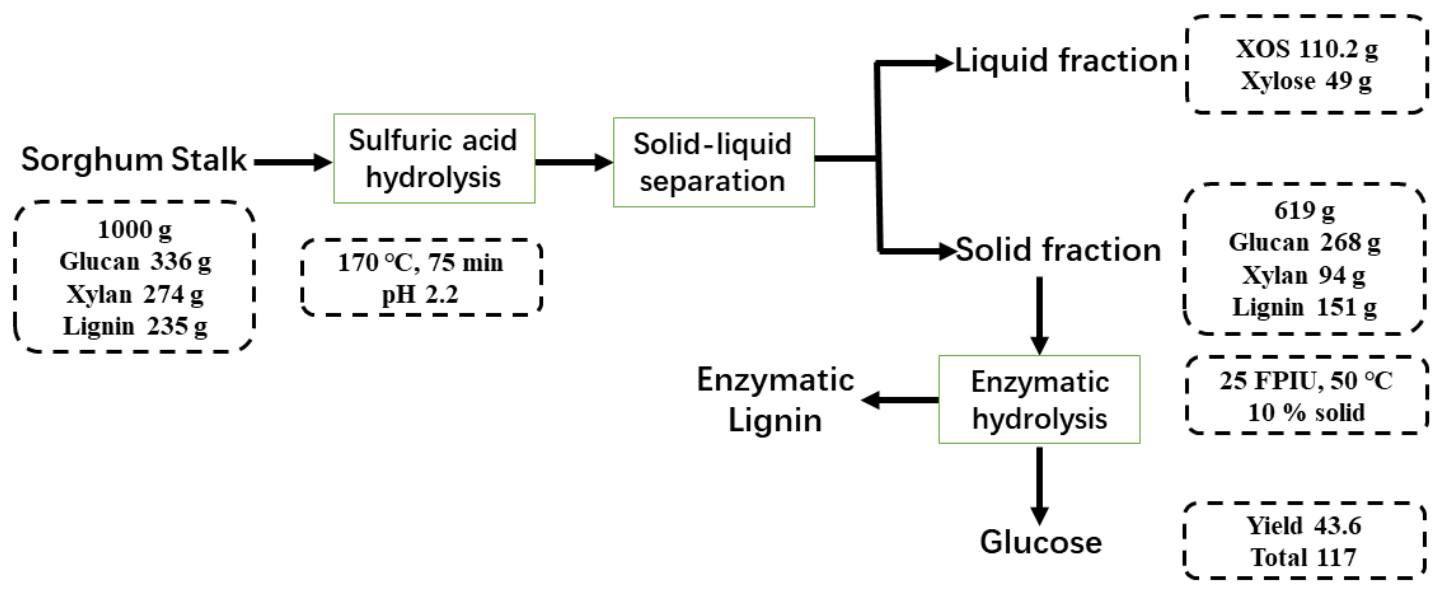

Figure 4. Mass balance of the co-production of XOS and glucose from SS.

\section{Conclusions}

In this work, the feasibility of preparing XOS and glucose from SS by different acid pretreatments were explored. It was found that the hydrolysis conditions such as types of acid, process time and temperature significantly influenced the XOS yield. The pretreatment using sulfuric acid ( $\mathrm{pH} 2.2)$ produced an optimum yield of XOS (39.2\%) at the process conditions of $170{ }^{\circ} \mathrm{C}$ and $75 \mathrm{~min}$. However, organic acid pretreatments were easier to get high content of XOS under several conditions compared to sulfuric acid pretreatment. Results also indicated that higher process time and temperature caused X5 and X6 to split into lower molecular mass such as X2, X3, and X4. An approximately of $110.2 \mathrm{~g}$ XOS and $117 \mathrm{~g}$ glucose were produced from $1000 \mathrm{~g}$ of SS based on mass balance during sulfuric acid pretreatment. To conclude, acid pretreatments exerted promising effects for facilitating coproduction of XOS and glucose. In the future work, the effects of lignin in SS on the depolymerization of xylan and the production of xylose oligosaccharides during different acid pretreatments would be explored.

Supplementary Materials: The following supporting information can be downloaded at: https: / / www.mdpi.com/article/10.3390/polym14040830/s1, Figure S1: Mass balance of the co-production of XOS and glucose using acetic acid pretreatment from SS; Figure S2: Mass balance of the coproduction of XOS and glucose using gluconic acid pretreatment from SS; Figure S3: Mass balance of the co-production of XOS and glucose using oxalic acid pretreatment from SS.

Author Contributions: Data curation, X.Y., H.Y., X.X. and Y.T.; Formal analysis, X.L.; Funding acquisition, Y.S. and M.Z.; Writing-original draft, X.Y.; Writing-review \& editing, X.L., Y.S., Y.T. and M.Z. All authors have read and agreed to the published version of the manuscript. 
Funding: The authors are grateful for the support of National Natural Science Foundation of China (Grant No. 12004178), Natural Science Foundation of Jiangsu Province (BK20210623, BK20211356), China Postdoctoral Science Foundation (Grant No. 2021M691579), Natural Science Foundation of Jiangsu Higher Education Institution (Grant No. 20KJD460003), Scien-tific Research Foundation for the Introduction of talent of Nanjing Vocational University of Industry Technology (Grant No. YK20-14-01), Scientific Research Project of Hunan Provincial Department of Education (20C1903) and Extension Project of Forestry Scientific and Tech-nological Achievements of the State Forestry and Grassland Administration ([2019]25).

Institutional Review Board Statement: Not application.

Informed Consent Statement: Not application.

Data Availability Statement: The data presented in this study are available on request from the corresponding author.

Acknowledgments: The authors are grateful for the support of Natural Science Foundation of Jiangsu Province (BK20210623).

Conflicts of Interest: The authors declare no conflict of interest. The funders had no role in the design of the study; in the collection, analyses, or interpretation of data; in the writing of the manuscript, or in the decision to publish the results.

\section{References}

1. Abuhay, A.; Mengie, W.; Tesfaye, T.; Gebino, G.; Ayele, M.; Haile, A.; Yillie, D. Opportunities for new biorefinery products from Ethiopian ginning industry by-products: Current status and prospects. J. Bioresour. Bioprod. 2021, 6, 195-214. [CrossRef]

2. Chen, Z.; Gao, H.; Li, W.; Li, S.; Liu, S.; Li, J. Research progress of biomass-based optical materials. J. For. Eng. 2020, 5, 1-12.

3. Yang, J.; Si, C.; Liu, K.; Liu, H.; Li, X.; Liang, M. Production of levulinic acid from lignocellulosic biomass and application. J. For. Eng. 2020, 5, 21-27.

4. Linan, L.Z.; Cidreira, A.C.M.; da Rocha, C.Q.; de Menezes, F.F.; de Moraes Rocha, G.J.; Paiva, A.E.M. Utilization of acai berry residual biomass for extraction of lignocellulosic byproducts. J. Bioresour. Bioprod. 2021, 6, 323-337. [CrossRef]

5. Cao, R.; Xu, Y. Efficient preparation of xylonic acid from xylonate fermentation broth by bipolar membrane electrodialysis. Appl. Biochem. Biotechnol. 2019, 187, 396-406. [CrossRef]

6. Huang, C.; Ragauskas, A.J.; Wu, X.; Huang, Y.; Zhou, X.; He, J.; Huang, C.; Lai, C.; Li, X.; Yong, Q. Co-production of bio-ethanol, xylonic acid and slow-release nitrogen fertilizer from low-cost straw pulping solid residue. Bioresour. Technol. 2018, 250, 365-373. [CrossRef]

7. Spinace, M.A.; Lambert, C.S.; Fermoselli, K.K.; De Paoli, M.A. Characterization of lignocellulosic curaua fibres. Carbohydr. Polym. 2009, 77, 47-53. [CrossRef]

8. Patel, A.; Shah, A.R. Integrated lignocellulosic biorefinery: Gateway for production of second generation ethanol and value added products. J. Bioresour. Bioprod. 2021, 6, 108-128. [CrossRef]

9. Manmai, N.; Unpaprom, Y.; Ponnusamy, V.K.; Ramaraj, R. Bioethanol production from the comparison between optimization of sorghum stalk and sugarcane leaf for sugar production by chemical pretreatment and enzymatic degradation. Fuel 2020, 278, 118262. [CrossRef]

10. Quiñones, T.S.; Retter, A.; Hobbs, P.J.; Budde, J.; Heiermann, M.; Plöchl, M.; Ravella, S.R. Production of xylooligosaccharides from renewable agricultural lignocellulose biomass. Biofuels 2015, 6, 147-155. [CrossRef]

11. Zhou, X.; Xu, Y. Integrative process for sugarcane bagasse biorefinery to co-produce xylooligosaccharides and gluconic acid. Bioresour. Technol. 2019, 282, 81-87. [CrossRef] [PubMed]

12. Tong, X.Y.; Li, Q.; Chen, W.Q.; Zhao, L.G. Alkali extraction of xylan from poplar sawdust and preparation of xylooligosaccharide by enzymatic hydrolysis. J. For. Eng. 2020, 5, 61-68.

13. Samanta, A.K.; Jayapal, N.; Jayaram, C.; Roy, S.; Kolte, A.P.; Senani, S.; Sridhar, M. Xylooligosaccharides as prebiotics from agricultural by-products: Production and applications. Bioact. Carbohydr. Diet. Fibre 2015, 5, 62-71. [CrossRef]

14. Ofori-Boateng, C.; Lee, K.T. Comparative thermodynamic sustainability assessment of lignocellulosic pretreatment methods for bioethanol production via exergy analysis. Chem. Eng. J. 2013, 228, 162-171. [CrossRef]

15. Wang, Y.; Cao, X.; Zhang, R.; Xiao, L.; Yuan, T.; Shi, Q.; Sun, R. Evaluation of xylooligosaccharide production from residual hemicelluloses of dissolving pulp by acid and enzymatic hydrolysis. RSC Adv. 2018, 8, 35211-35217. [CrossRef]

16. Zhao, X.; Morikawa, Y.; Qi, F.; Zeng, J.; Liu, D. A novel kinetic model for polysaccharide dissolution during atmospheric acetic acid pretreatment of sugarcane bagasse. Bioresour. Technol. 2014, 151, 128-136. [CrossRef]

17. Wang, J.Y.; Jia, L.L.; Xu, Y.; Zhang, J.H. Effect of acetic acid-sulfite two-step pretreatment on the adsorption of poplar lignin toward cellulase. J. For. Eng. 2021, 6, 111-119.

18. Gao, Y.Q.; Li, Y.Y.; Ren, R.Q.; Chen, Y.; Gao, J.M. Effect of weak acid modification on the structure and properties of heat-treated Chinese fir. J. For. Eng. 2021, 6, 49-55. 
19. Zhang, H.; Xu, Y.; Yu, S. Co-production of functional xylooligosaccharides and fermentable sugars from corncob with effective acetic acid prehydrolysis. Bioresour. Technol. 2017, 234, 343-349. [CrossRef]

20. Sheng, Y.; Tan, X.; Gu, Y.; Zhou, X.; Tu, M.; Xu, Y. Effect of ascorbic acid assisted dilute acid pretreatment on lignin removal and enzyme digestibility of agricultural residues. Renew. Energy 2021, 163, 732-739. [CrossRef]

21. Lin, Q.; Li, H.; Ren, J.; Deng, A.; Li, W.; Liu, C.; Sun, R. Production of xylooligosaccharides by microwave-induced, organic acid-catalyzed hydrolysis of different xylan-type hemicelluloses: Optimization by response surface methodology. Carbohyd. Polym. 2017, 157, 214-225. [CrossRef] [PubMed]

22. Sluiter, A.; Hames, B.; Ruiz, R.; Scarlata, C.; Sluiter, J.; Templeton, D.; Crocker, D.L.A.P. Determination of structural carbohydrates and lignin in biomass. Lab. Anal. Proced. 2008, 1617, 1-16.

23. Xu, Y.; Fan, L.; Wang, X.; Yong, Q.; Yu, S.Y. Simultaneous separation and quantification of linear xylo- and cello-oligosaccharides mixtures in lignocellulosics processing products on high-performance anion-exchange chromatography coupled with pulsed amperometric detection. Bioresources 2013, 8, 3247-3259. [CrossRef]

24. Zhang, H.; Zhou, X.; Xu, Y.; Yu, S. Production of xylooligosaccharides from Waste Xylan, obtained from viscose fiber processing, by selective hydrolysis using concentrated acetic acid. J. Wood Chem. Technol. 2017, 37, 1-9. [CrossRef]

25. Noureddini, H.; Byun, J. Dilute-acid pretreatment of distillers' grains and corn fiber. Bioresour. Technol. 2010, 101, 1060-1067. [CrossRef] [PubMed]

26. Han, J.; Cao, R.; Zhou, X.; Xu, Y. An integrated biorefinery process for adding values to corncob in co-production of xylooligosaccharides and glucose starting from pretreatment with gluconic acid. Bioresour. Technol. 2020, 307, 123200. [CrossRef]

27. Zhang, Q.; Zhao, M.; Xu, Q.; Ren, H.; Yin, J. Enhanced enzymatic hydrolysis of sorghum stalk by supercritical carbon dioxide and ultrasonic pretreatment. Appl. Biochem. Biotechnol. 2019, 188, 101-111. [CrossRef] 